\title{
The Lived Experiences of Academically High Achievers of Menieato Elementary School: A Phenomenological Approach
}

\section{Demessew Alemu Woldetsadik}

dalemu12@yahoo.com

\author{
Mutendwahothe Walter Lumadi \\ Department of Curriculum and Instruction, College of Education, \\ University of South Africa, South Africa, \\ Email: lumadmw@unisa.ac.za
}

\section{Doi:10.5901/mjss.2014.v5n20p2871}

\begin{abstract}
High academic achievers engage themselves in academic activities, while in school or at home, that can lead to better academic results. The wider academic experiences they acquire during their schooling time can be imitated by the other students of a school. An organized effort exerted by school leaders, teachers and parents can create a better situation for academically weak students to make use of these experiences. A qualitative phenomenological design was employed in this study to explore the lived academic experiences of the interviewees. The research approach provided participants with an opportunity to describe their academic experiences as they understand it.
\end{abstract}

Keywords: academic experience, classroom learning activities, out of class activities, home activities, peer influence, experience transfer/sharing.

\section{Introduction}

A school is a place where students can gain knowledge, develop skill and alter their behaviour. In doing this, students enter into a social relation with their teachers, classmates, students and with other school community members. All these social forces exert their own influence in the life of school students. As a result, students make gradual change in their personality. This fact becomes clear when one considers the time range for students stay in schools. Thus, change is an inescapable natural process that can be experienced by all students. The change, in its totality, can be judged in terms of social acceptable behaviours. In conformity with the social norms, people learn by imitating others. However, people don't learn only the acceptable social behaviours. They may learn some anti-social behaviours. Knowledge gained in this way will have the chance to be transferred to another situation. This may continue all the time and everywhere.

In the same vein, we can argue that students spend most of their time by learning. This can happen in different situations. It can be seen in groups while with others. However, this kind of activity is vulnerable to social pressure by others. For instance, peer influence seems high during the time of puberty and adolescence period. This kind of social group can play a role in the academic life of students. Students in a class, either in group or individually, can make influence on some parts of life. As it can be observed in schools, students may do assignments in groups, may participate in clubs and may study together. This process continues till the end of students' schooling time and may force them to act even in their later life. Consequently, one can say that a peer group is a special social force that can exert a change on students' academic life.

A careful study on peers' influences can contribute positive results to academic activities. This is due to the fact that it can focus on better academic experiences of students. Eventually, it can have a potential to share academic experiences for others. This study has attempted to investigate the experiences of high academic achievers of an elementary school. We believe that such an attempt enable school leaders, teachers, parents and students to pay heed to best academic experiences of high achievers and should think about ways of scaling up the knowledge.

\section{Conceptual Framework for the Study}

The aim of this study was to look at the academic experiences of students in an elementary school. It specifically focused on students'; 


\section{Classroom learning activities}

2. Out of class activities and

3. Home activities.

In each of the aforementioned situations, there were some academic activities exercised by students. These activities have the potential to make change in the academic life of students. This process will bring an effect on the acquisition of experience on academic matters by students.

Thus, the concept of 'experience' is widely employed in this study to recount students' academic achievements in the different situations. Most of the time, the term is used to describe the process of learning. In relation to this, John Dewey called the concept as, 'learning by doing', while Wolfe and Byrne used to label it as, 'experienced-based learning'. However, there are different viewpoints regarding the acquisition of knowledge.

Arguments regarding the acquisition of knowledge have been critical for a long time in both cognitive and behavioral theories. Accordingly, the cognitive theory emphasizes on the role of mind (mainly on its function) during the learning process. But, the behavioral theory attaches more value to environmental factors (more specifically by considering the stimulus-response bondage) alone. However, the experiential learning theory, proposed by Kolb, gives importance to both sides of the arguments. Accordingly, he says that experiences emanating from both cognitive and environmental factors can play role in gaining knowledge. Furthermore, he claims that experience can be created or recreated and is believed to be transformed without being an independent entity (Kolb, 1984).

In a school situation students continuously engage themselves in the learning process. It can be observed when they do assignments, read books and do other related academic activities. Obviously, this is a regular process exercised by most of the students in schools. However, the habit of doing these things can't happen at a time. It needs careful observation and systematic exercise. All these efforts lead students to make their own meaning/understanding of the activities. Besides, it enables them to reach at a level of sharing their own experiences and to become a continuous process.

The process of sharing experience is believed to comprise of four series but interrelated stages (Kolb, 1984). In the first stage, the learner should engage himself/herself in a new experience. Secondly, he/she should actively reflect on that experience. Ultimately, he/she should conceptualize and integrate it with his/her past experiences. We can clarify this in relation to students' regular activities in school. In a school situation, most of the time, students choose activities that go with their interest. If it interests them, they take time to make their own reflection. This leads them to use information to describe/explain it the way they understand it. Eventually, they come to own the whole process and start to react accordingly. However, this doesn't mean that students are simple recipients of knowledge. Instead, they can react, reflect, analyze, synthesize and can evaluate their achievements. This view is shared with the constructivists since they assert that knowledge can be acquired through an active involvement than simple observation.

Experiences developed in different ways and situations can form personal gains and can provide concrete, publicly shared reference points for testing their implications and validate the ideas created during the learning process. Experiences acquired in this way can fully, concretely or abstractly be shared to the other people (Kolb, 1984). This goes with the principle of knowledge transfer. As it is known, knowledge can be transferred from one person to another when one dares to imitate the other. In relation to this, we can pose questions like; which academic activities of students form better experiences in a school and how can they be shared by others? with what conditions and assumptions? With what degree of transferability? In view of this, Battersby and Gordon (2006) have cited some of the specific situations that can develop experience within the school context. They stated varied sources of experience. They believe that the identification of best characteristics of both teachers and students, either in group or individually, in the first place requires recollecting observation. Accordingly, students are supposed to learn and gain experience by observing teacher-pupil relationship, understand the classroom management, perceive the different teaching styles and realize students' learning process. Experience can also be developed by imitating/observing other people's activity in a school environment. Thus, as there are varied experiences of people, students can imitate people whose experiences attract them the most.

On the other hand, the external situations that give rise to the development of students' experiences are categorized as 'after school programs'. In fact, some of these activities are supposed to focus on academic and others on recreational and cultural programs. Some of the contents of after-school programs include sport activities, club participation and tutorial activities. It is true that these activities have implications on the academic activities of students (Gurdner, Roth \& Brooks-Gunn, 2009).

\section{Research Methodology}

There is no uniform research design applicable to all qualitative research problems. In consequence, different qualitative 
researchers resort to the application of a range of qualitative strategies depending on the nature of the research problem they identified. Accordingly, the research methodology employed in this qualitative research is the phenomenological research. As it may be known, phenomenology is a philosophical approach that studies people's experience based on the context they live. The phenomenological research approach enabled the researchers to describe, reflect and interpret the academic experiences of high achievers. In relation to this, the researchers studied students' experiences from their own perspective than from his viewpoint. This kind of research approach is believed to be effective at bringing the experiences and perceptions of individuals from their own perspective. The research approach can also be applied to single cases or deliberately selected samples (Lester, 1999).

The researchers selected high academic achievers of grade five to eight students of Menieato private elementary school in Addis Ababa. They were selected based on their interest to take part in the study. Consequently, they took part in the study during their free time-the summer vacation. High ranking students (who ranked one to three) of the school, in their respective grades for the last three consecutive years, were selected in the study. The data was secured from the school administration in collaboration with homeroom teachers. Based on the criterion set by the researchers, one student from each grade for the study was selected for FGD program. In fact, the FGD program was finally arranged with the consent of the selected students. The following table shows the background information regarding the selected students.

Table 1: Background Information of Participants

\begin{tabular}{|c|c|c|c|c|c|c|c|}
\hline \multirow{2}{*}{ Student number } & \multirow{2}{*}{ Grade } & Number of & \multicolumn{2}{|c|}{ Sex } & \multicolumn{3}{|c|}{ Rank of the selected students in the previous three years } \\
\cline { 4 - 8 } & & students sampled & M & F & 2011 & 2012 & 2013 \\
\hline 1. & 4 & 1 & X & --- & First & First & second \\
\hline 2. & 6 & 1 & --- & $X$ & second & First & Third \\
\hline 3. & 7 & 1 & $X$ & --- & second & second & First \\
\hline 4. & 8 & 1 & --- & $X$ & Third & First & second \\
\hline
\end{tabular}

The nature of the investigation required the researchers to take time to stay with the selected students for three weeks time. This strategy enabled the researchers to seek students' interest to participate in the study and to gain their informed consent by providing permission to be interviewed in group (FGD). The researchers had taken time to establish better social relation with students before he collected the data. Lastly, he conducted FGD with all the selected students. During this time, he took notes of conversations with students. Besides, the researchers arranged interview sessions with each of the students selected for the study.

The researchers were careful to avoid asking direct questions to the students while collecting the data. Instead, he used to tell them stories related with their academic experiences. He made this technique to motivate the interviewees to narrate their own experiences. He ensured students to feel comfortable while telling their academic stories. One way to accomplish this task was by telling students not to mention their real names during the interview process. During the FGD process the students were encouraged to talk more about their academic experiences.

Upon the completion of the interview process, interview texts were prepared by the researchers for each interviewee regarding his/her academic experiences. The researchers put interview texts of each interviewee under a separate folder. Eventually, the researchers extracted meaning/s from text passages of each interviewee. Also, the theme/s expressed in the story of each interviewee was/were taken out separately from each text. Finally, the links between the meanings and themes were established by coding each interviewee's text. At last, categories of description of experiences that have implications on future academic plans of the students of the school were identified from the analysis of the academic experiences of high achievers. In fact, what categories one decides to form depend on the aim of the study and the researchers' interest. However, they need to be generated from the given data (Woods, 2006). Hence, the categories were established based on the learning activities of the selected students in both inside outside classrooms, including their home activities. Consequently, the academic experiences of the students were made to link and differentiate from each other by variations and meanings of the issues.

\section{The Research Findings}

Based on the data gathered, the researchers categorized the major findings of the study under the following major headings: 


\subsection{Classroom learning activities}

The behaviours of the selected students that are observed in the classroom were put under this category. Thus, the selected high academic achievers have better concept of school, attentive to class attendance, reach school and complete class works on time, participate in class discussions, study ahead of time, conform to school rules, attentive to teachers' explanations, use their time wisely, don't want spend time on opposite sex affairs, imitates model teachers and students, know the life history of known personalities from global and local perspectives and sets goals ahead of time.

\subsection{Out of class activities in the school}

Students' experiences outside the classroom are listed under this category. The selected high academic achievers described their behaviour in paying attention to school notice, reluctant to take part in extracurricular activities, make frequent visit to the library, discuss academic issues and recapitulate the main points of the lesson during recess time, form their own social group, try to improve their language skill by communicating in English, rarely discuss on issues related to films, volunteer to support academically weak classmates and don't use snide remarks.

\subsection{Home activities}

Students' academic experiences that have their roots in the home are made to fall under this category. Regarding home activities, the selected students expressed their lack of interest in current affairs, balance time when using technological devices, show interest in assisting parents, pay heed to parental advice, take care of their own health conditions, share knowledge to siblings, classmates and friends, spend much of their time in studying and doing home works, not interested to take part in social activities, take care of their learning materials, chose friends based on academic performance and exchange ideas on academic issues.

\section{Discussion}

A clear difference can be observed between academically strong and weak students regarding the activities they do. This difference could be observed while they are engaged in the classrooms, out of classrooms and at home activities. However, all these situations enable students to learn a lot. It seems clear that learning can take place not only in school but also in multiple contexts and valued practices of everyday lives across the life span of people (Banks et al, 2007). Students can learn, in both formal and non-formal situations, if they have an interest to learn. The degree of student commitment to learn and the effort they exert can determine their engagement in the school activities. The meaning students attach to school activities has a link with the degree of their participation in the academic and non-academic programs. Research findings have shown that academically strong students show more engagement in academic activities than the weak ones. This makes them to establish good relationship with school staff and with the other students. This leads them to enjoy in school activities (Willms, 2003).

Student engagement in school activities can be expressed in various forms such as; school and class attendance, preparedness for class, completing homework, attending lessons, and involvement in extra-curricular activities. However, this kind of behaviour can't be observed in low academic achieving students (Willms, 2003). Schools' conditions at times can influence students' engagement, which can ultimately lead them to withdraw from school activities due to boredom, poor attendance, or low achievement (Rumberge,2011).A solution to improve the participation of students in school programs can be done by applying a variety of academic programs. Also, measures to change academically related attitudes and beliefs, learning behaviours can lead to show a positive approach or commitment to learning and attendance at school (Gardner, Roth \& Brooks-Gunn, 2009). Other measures such as parental attendance at school events and participation in parent-teacher organizations can enhance students' engagement. Moreover, activities that take place in the home that support student achievement, such as parental homework help and discussions about school issues between parents and children can bring positive results (Jordan, Orozco \& Averett, 2002) .B

\section{Conclusion}

This study explored the lived experiences of high academic achievers of Menieato elementary school in Addis Ababa. It has become clear from the study that academic achievers spend their time, both in school and out of school, engaging themselves in academic related activities. The academic experiences of these students is helpful not only for them but for 
the other students of a school. This is due to the fact that they have a lot of academic experiences to share for the others.

Findings of the study have shown that high academic achievers' experiences/behaviours (related with academic activities in school) can be observed from the activities they perform in the school. Accordingly, they engage themselves in academic activities in the class, out of class and at home. Thus, the behaviour expressed overtly can be imitated and reflected by their classmates or by the other students of the school. School leaders, teachers and parents can play a role by facilitating opportunities to the other students of a school for imitation.

\section{Recommendation}

The need for experience sharing is crucial for school students. As it may be known, students have varied experiences in the different aspects of their life. For instance, in terms of academic achievements they may show better performance in the subjects they learn in schools. They may not, in fact, demonstrate the same academic results in all subjects they learn. The academic behaviour of high achievers can be observed while performing different school activities. Most of the activities, they are engaged in, could be observed by others. This process enables school students to strengthen their social relation and exchange experiences. It is true that the behaviour of high academic achievers can be imitated by the other students of a school. However, a collective effort is required by all stakeholders to facilitate the transfer of experiences. Thus, carefully designed strategies should be put in place by school leaders, teachers and even by parents. This group of people should have the habit of discussing on the issue. Besides, there should be a regular monitoring and evaluation system in the school.

\section{References}

Banks (2007) Learning in and out of school in diverse environments: Life long, Life wide, Life deep. University of Washington: The learning in Informal and Formal Environment Center.

Battersby,J. and Gordon, J.(eds.)(2006) Preparing to teach: Learning form experience. New York: Routledge.

Gardner, M., Roth J., and Brooks-Gunn, J.(2009) Can After-School Programs Help Level the academic Playing Field for Disadvantaged Youth. Colombia: Colombia University Press.

Gurdner,M., Roth, J. and Brooks-Gunn,J.(2009) Can after-school programs help level the playing field for disadvantaged youth? Research Review No.4. Columbia University Press: Columbia.

Jordan, C., Orozco, E. and Averett, A.(2002) Emerging Issues in Schools, Family and Community. Texas: Southwest Educational Development Laboratory.

Kolb,D.(1984) Experiential learning: Experience as the source of learning and development.

$\mathrm{NJ}$ : Prentice Hall.

Lester, S (1999) An introduction to phenomenological research. Taunton UK, Stan Lester Developments (www.sld.demon.co.uk/ resmethy.pdf. [Accessed on 11/18/2013]

Rumberge,R.(2011) Why Students Drop Out of High School and What Can be Done About It? Harvard University Press.

Vos,A.,Strydom,H., Fouche,C. and Delport. C(2011) Research at the grass roots: For the social sciences and human service professions. $4^{\text {th }}$ ed. Pretoria: Van Schaik publishers.

Willms, J.(2003) Student Engagement At School: A sense of belonging and participation. OECD (Organization For Economic Cooperation And Development).

Woods,P.(2006) Successful Writing For Qualitative Researchers (2nd ed.). London: Routledge Falmer. 